\title{
Determination of Levels of Asbestos Fiber in Cosmetic and Non-Cosmetic Products Sold within Enugu Metropolis-Enugu State, Nigeria
}

\section{Onyeka Okeke1, Harold Chinedu Okeke ${ }^{2}$, Ernest Ezeh ${ }^{3}$, Charles Chukwubuikem Aniobi4, Uchechi Rowland Imoh ${ }^{1}$}

${ }^{1}$ Plastic Production Unit, Scientific Equipment Development Institute, Akwuke, Nigeria

${ }^{2}$ Department of Geological Sciences, Nnamdi Azikwe University Awka, Nigeria

${ }^{3}$ Department of Chemical Engineering, Nnamdi Azikwe University, Awka, Nigeria

${ }^{4}$ Department of Community Medicine, University of Nigeria, Enugu Campus, Enugu, Nigeria

Email: onyekaokeke207@yahoo.com

How to cite this paper: Okeke, O., Okeke, H.C., Ezeh, E., Aniobi, C.C. and Imoh, U.R. (2020) Determination of Levels of Asbestos Fiber in Cosmetic and Non-Cosmetic Products Sold within Enugu Metropolis-Enugu State, Nigeria. Journal of Environmental Protection, 11, 862-871. https://doi.org/10.4236/jep.2020.1110054

Received: September 11, 2020

Accepted: October 18, 2020

Published: October 21, 2020

Copyright $\odot 2020$ by author(s) and Scientific Research Publishing Inc. This work is licensed under the Creative Commons Attribution International License (CC BY 4.0).

http://creativecommons.org/licenses/by/4.0/

(c) (i) Open Access

\begin{abstract}
Studies were carried out to determine asbestos fiber levels in cosmetic (talc powder) and non-cosmetic (gauze pad, plastic filler and ceiling tiles) products sold in market outlets within Enugu, metropolis, Enugu State, Nigeria, using standard established procedures. The samples were pretreated based on its physical make-up and the asbestos fiber levels determined using scanning electron microscopy (SEM) with energy dispersing spectroscopy techniques. The mean range of asbestos fiber was, $0.02-0.06 ; 0.01-0.05 ; 0.01-0.04$ and $0.03-0.06 \mathrm{f} / \mathrm{cc}$ for talc powder, gauze pads, plastic filler and ceiling tile samples respectively. The mean levels of asbestos fibers in the studied samples were within the recommended permissible limits. The samples contain asbestos fiber in the following decreasing order: ceiling tiles $>$ talc powders $>$ gauze pads > plastic fillers. Asbestos fiber was found present in the investigated local and foreign items sold in market outlets within the metropolis. This study shows that despite the ban on the use of asbestos in the industry in the manufacture of items meant for human use, its enforcement appears weak and lethargic and this could portend health danger especially in the use of produced items with high asbestos fiber friability such as talc powder.
\end{abstract}

\section{Keywords}

Asbestos Fiber, Talc Powder, Plastic Filler, Ceiling Tile and Gauze Pad

\section{Introduction}

Asbestos is a naturally occurring fibrous mineral. It is the name used to describe 
a group of fibrous hydrous silicates which have outstanding physical properties including high tensile strength, heat and electrical insulation resistance to biodegradation, non-combustibility, stability in the high $\mathrm{pH}$ range of the cement matrix, low electrical conductivity and a very powerful absorbant [1].

The principal varieties of asbestos used commercially are chrysolite (hydrous magnesium silicate), a serpentine mineral, and crocidolite (iron and sodium silicate) and amosite (iron and magnesium silicate), both of which are amphiboles. Anthophyllite, tremolite and actinolite asbestos are also amphiboles, but they are rare [2].

Asbestos are an important component in a variety of building materials, including loose-fill, insulations, acoustic and thermal sprays, pipe and boiler wraps, paints, flouring product materials and cementation products [3]. The main use of asbestos fibers is in the manufacture of asbestos cement products which is employed in fine protection panel, corrugated panels for roofing and cladding, roof tiles, fire sounds, rain water goods, water tanks and water pipe work [2]. According to [3], the second largest use of asbestos in the United States of America is in the asphalt and vinyl floor file manufacturing industry due to their durability and impermeability to water. Chrysolite asbestos fibers were once used in the manufacture of automobile brake pads, shoes, and clutch disk; however replacement in the use of the asbestos fibers in the manufacture of these products was done with materials such as ceramic, carbon, and metallic and aramid fiber.

Laboratory machines and tools such as ovens, centrifuges, Bunsen mats and gauze pads have been produced using asbestos fibers [4]. Asbestos has been declared harmful to health, and its use restricted or banned in more than 52 countries [5].

During the twentieth century, asbestos was widely used in buildings and industrial installations but the evidence of the health risks that it can cause due to the inhalation of the fibers has pushed health authorities to issue stringent norms to avoid industrial and domestic applications [6]. Important and big countries such as China, India, Russia Kazakhstan, Brazil but also Canada, Zimbabwe and Colombia and Nigeria are still producers and consumers of asbestos materials [5]. The mere presence of asbestos does not always represent a risk, but it can become dangerous if it dispenses its fibers in the surrounding environment for example due to mechanical or thermal stress.

The most common way for asbestos fibers to enter the body is through breathing. In fact, asbestos containing material is not generally considered to be harmful unless it is releasing dust or fibers into the air where it can be inhaled or ingested [7]. Once they are trapped in the body, the fibers can cause health problems.

Asbestos is most hazardous when it is friable. The term friable means the asbestos is easily crumbled by hand, releasing fibers into the air [8]. Damage and deterioration will increase the friability of asbestos containing materials.

Health risks due to exposure to different asbestos types are dependent on the 
fibrous structure of the materials thus asbestos types which are liable to form fibers less than 3 microns in diameter, principally the amphiboles are the most hazardous while fibers length longer than 8 microns poses greatest hazardous risk [8].

Because it is hard to destroy asbestos fibers, the body cannot break them down or remove them once they are lodged in the lungs or body tissue hence remain for a long time, where they can cause diseases. General industrial employees may be exposed to asbestos during the manufacture of asbestos containing products or when performing brake and clutch repairs while in the construction industry, exposure occurs when workers disturb asbestos containing materials during the renovation or demolition of buildings constructed with asbestos-containing materials [9].

Epidemiological studies mainly an occupational (mining and milling), manufacturing or product application groups, have established that all types of asbestos fibers may be associated with asbestosis, bronchial carcinoma and mesothelioma [10].

Asbestosis is a serious, chronic, non-cancerous respiratory disease and in its advanced stages causes cardiac failure. There is no effective treatment for asbestosis, the disease is usually disabling or fatal [7]. Bronchial carcinoma causes the largest number of deaths related to asbestos exposure [11]. The incidence of bronchial carcinoma (lung cancer) in people who are directly involved in the mining, milling, manufacturing and use of asbestos and its products is much higher than in the general population. The most common symptoms of lung cancer are coughing, breathing difficulty, persistent chest pains and anemia [12].

Mesothelioma is a rare form of cancer that most often occurs in the thin membrane linings of lungs, chest, abdomen and (rarely) heart. Virtually all cases of mesothelioma are linked with asbestos exposure and the latent period for the disease is very long-an average of 30 years from first exposure [13]. According to global estimates, resulting from occupational exposures at least 107,000 people die each year from asbestos related lung cancer, mesothelioma and asbestosis while nearly 400 deaths have been attributed to non-occupational exposure to asbestos [14].

The likelihood of having asbestos related disease has been attributed to be dependent on the amount and duration of exposure, life style (smokers) and age (especially younger people) [8].

Most developing countries like Nigeria still widely consume asbestos containing materials especially on account of its affordability, fire resistance and durability.

Today, anthropogenic and natural processes are contributing to the presence of asbestos and elongated mineral particles of nonasbestos amphibole and serpentine in the air and water of urban, rural and environments.

Due to its adverse health impacts, studies was therefore carried out to determine the levels of asbestos fibers in cosmetic (talc powders), non cosmetic (paint fillers, ceiling tiles and gauze pads) products sold in markets within Enugu Me- 
tropolis, Enugu State, Nigeria.

\section{Materials and Methods}

Twenty sample products (talc powder, gauze pad, plastic fillers and ceiling tiles) were purchased from different market outlets within Enugu Metropolis. Talc powder samples were denoted $\mathrm{TP}_{1}, \mathrm{TP}_{2}, \mathrm{TP}_{3}, \mathrm{TP}_{4}, \mathrm{TP}_{5}$ and $\mathrm{TP}_{6}$ to represent the countries of origin which were, United States of America, Nigeria, Nigeria, China, France and India respectively.

The gauze pad samples were denoted $\mathrm{GP}_{1}, \mathrm{GP}_{2}, \mathrm{GP}_{3}, \mathrm{GP}_{4}$ and $\mathrm{GP}_{5}$ to represent Brazil, Japan, South Korea, Indonesia and China respectively as countries of origin. $\mathrm{PF}_{1}, \mathrm{PF}_{2}, \mathrm{PF}_{3}$ and $\mathrm{PF}_{4}$ represented plastic filler samples manufactured in $\mathrm{Ni}$ geria, China, Indonesia and India. The ceiling tile samples were denoted $\mathrm{CT}_{1}$, $\mathrm{CT}_{2}, \mathrm{CT}_{3}, \mathrm{CT}_{4}$, and $\mathrm{CT}_{5}$, to represent France, Japan, China, India and Indonesia respectively as countries of origin.

\section{Sample pretreatment and quantification of asbestos fiber contents.}

Each of the samples was crushed, (except talc powder) and sieved with $50 \mu \mathrm{m}$ mesh and dried in an oven at $110^{\circ} \mathrm{C}$ for 24 hours. The samples were ashed in a muffle furnace for 6 hours at a temperature of between $300-500^{\circ} \mathrm{C}$. This was done to remove organic substances present in the samples. To remove minerals (such as dolomite, calcite, gypsum, magnetite, portlandite and brucite) that may be present in the samples, ashed samples were subjected to acid treatment using $\mathrm{HNO}_{3}$ and $\mathrm{HCLO}_{4}$ in the ratio of 3:2.

After the acid treatment, the samples were placed in scan slides. Asbestos concentration in the samples was determined using scanning electron microscopy (SEM) coupled with energy dispersing spectroscopy (EDS) techniques as described by [15] [16]. SEM-EDS techniques were used because of its better resolution and ability to detect asbestos fibers even in low concentration ranges.

\section{Results and Discussion}

Results of Table 1 show that mean levels of asbestos fiber in talc powder samples $\mathrm{TP}_{1}, \mathrm{TP}_{2}, \mathrm{TP}_{3}, \mathrm{TP}_{5}$, and $\mathrm{TP}_{6}$ were $0.06 \pm 0.02,0.03 \pm 0.00,0.02 \pm 0.00,0.05 \pm 0.00$, $\mathrm{ND}$ and $0.02 \pm 0.01 \mathrm{f} / \mathrm{cc}$ respectively. The order of decrease of asbestos fiber content in the samples were, $\mathrm{TP}_{1}>\mathrm{TP}_{4}>\mathrm{TP}_{2}>\mathrm{TP}_{3}>\mathrm{TP}_{6}$ as shown in Figure 1.

Talc powder is made from talc, a mineral made up mainly of the elements magnesium, silicon and oxygen. It is widely used in cosmetic products as body powder and adult body and facial powders.

According to [17], in its natural form, some talc contains asbestos, a substance known to cause cancer in and around the lungs when inhaled.

Some studies of talc miners and millers have suggested an increased risk of lung cancer and other respiratory diseases, while others have found no increase in lung cancer risk [18].

The study suggested that genital talcum powder use may slightly increase the risk of uterine cancer in women who are past menopause [19]. Only recently, 
Table 1. Mean asbestos fiber contents in talc powder samples sold within Enugu Metropolis.

\begin{tabular}{cc}
\hline Sample & Asbestos fiber content $(\mathbf{f} / \mathbf{c c})$ \\
\hline $\mathrm{TP}_{1}$ & $0.06 \pm 0.02$ \\
$\mathrm{TP}_{2}$ & $0.03 \pm 0.00$ \\
$\mathrm{TP}_{3}$ & $0.02 \pm 0.00$ \\
$\mathrm{TP}_{4}$ & $0.05 \pm 0.00$ \\
$\mathrm{TP}_{5}$ & $\mathrm{ND}$ \\
$\mathrm{TP}_{6}$ & $0.02 \pm 0.01$ \\
Permissible limits $[14]$ & 0.2 \\
\hline
\end{tabular}

$\mathrm{TP}=$ Talc powder; $\mathrm{ND}=$ Non detected.

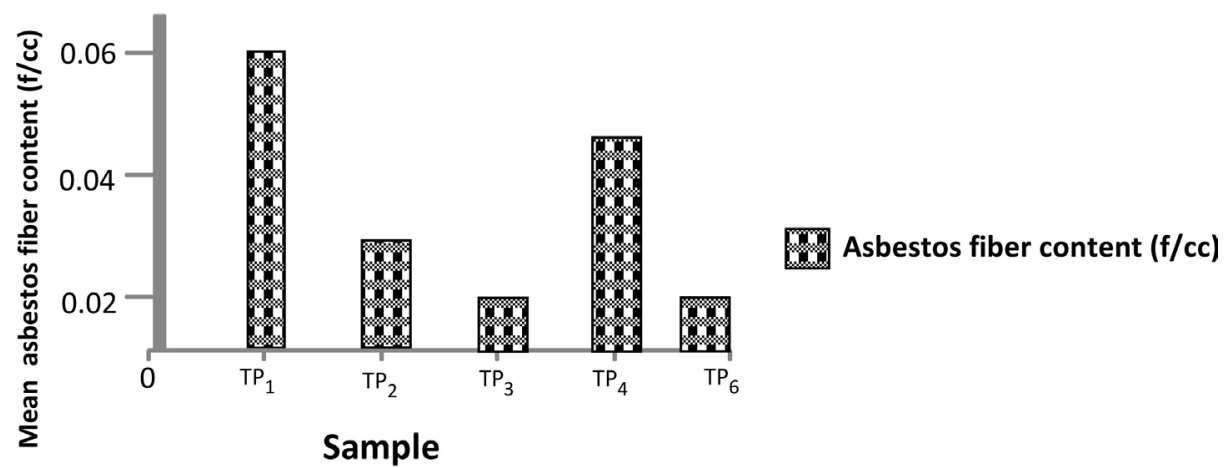

Figure 1. Bar chart representation of the mean asbestos fiber contents in the talc powder samples.

categorically on $12^{\text {th }}$ July, 2018, a Missouri jury ordered Johnson \& Johnson to pay a record $\$ 4.69$ billion to 22 women who alleged that the company talc-based products, including its baby powder, contains asbestos and caused them to development ovarian cancer [20].

The results of Table 1 show that the levels of asbestos in both the locally $\left(\mathrm{TP}_{2}\right.$ and $\left.\mathrm{TP}_{3}\right)$ and foreign $\left(\mathrm{TP}_{2}, \mathrm{TP}_{4}, \mathrm{TP}_{3}\right.$ and $\left.\mathrm{TP}_{6}\right)$ produced talc powder samples were within the permissible limits of $0.2 \mathrm{f} / \mathrm{cc}$

Results of Table 2 show that the mean levels of asbestos fiber in $\mathrm{GP}_{1}, \mathrm{GP}_{2}$, $\mathrm{GP}_{3}, \mathrm{GP}_{4}$ and $\mathrm{GP}_{5}$ were $0.05 \pm 0.01,0.03 \pm 0.00,0.04 \pm 0.01,0.01 \pm 0.00$ and 0.03 $\pm 0.01 \mathrm{f} / \mathrm{cc}$ respectively.

Figure 2 shows that gauze pad samples contain asbestos fiber in the following decreasing order; $\mathrm{GP}_{1}>\mathrm{GP}_{3}>\mathrm{GP}_{2}>\mathrm{GP}_{5}>\mathrm{GP}_{4}$.

All the studied gauze pad samples were foreign produced and the study shows that despite the ban on the use of asbestos materials in the manufacture of gauze pads among other laboratory equipment is still prevalent. Because of the very important insulating properties of asbestos, its addition in the production of laboratory equipment that risks corrosive attack from strong chemicals appears inevitable.

The levels of asbestos fibers in the studied gauze pad samples were within the 
Table 2. Mean asbestos fiber contents in gauze pad samples sold within Enugu Metropolis.

\begin{tabular}{cc}
\hline Sample & Asbestos fiber content $(\mathbf{f} / \mathrm{cc})$ \\
\hline $\mathrm{GP}_{1}$ & $0.05 \pm 0.01$ \\
$\mathrm{GP}_{2}$ & $0.03 \pm 0.00$ \\
$\mathrm{GP}_{3}$ & $0.04 \pm 0.01$ \\
$\mathrm{GP}_{4}$ & $0.01 \pm 0.00$ \\
$\mathrm{GP}_{5}$ & $0.03 \pm 0.01$ \\
Permissible limits $[14]$ & 0.2 \\
\hline
\end{tabular}

GP = Gauze pad

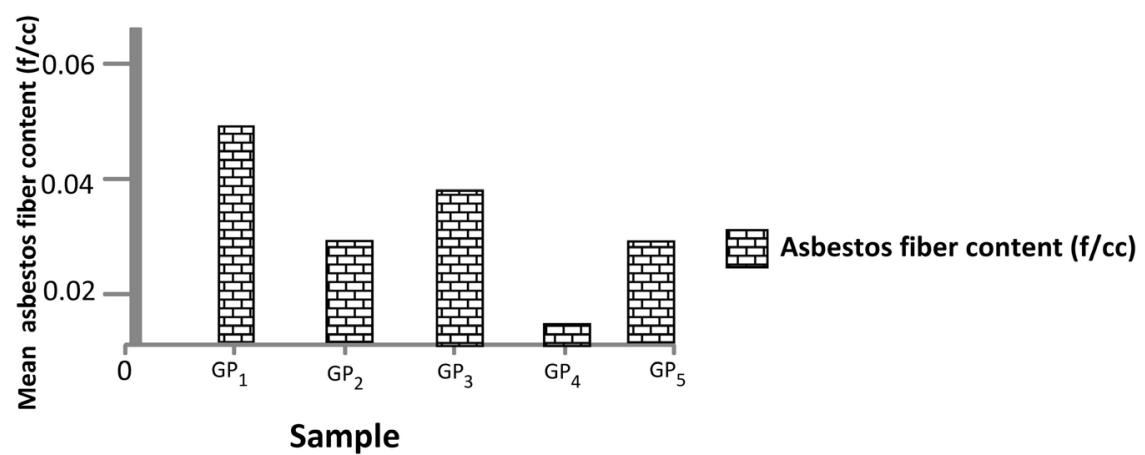

Figure 2. Bar chart representation of the mean levels of asbestos fiber in the gauze pad samples.

standard recommended permissible limits. Although the asbestos fibers in the gauze pad samples cannot be said to be friable but when broken or corroded can release asbestos fibers into the air and thus can result to harm.

Results of Table 3 show that the mean levels of asbestos fiber in the plastic filler samples sold within Enugu metropolis Enugu, Nigeria were, $0.03 \pm 0.01,0.01$ $\pm 0.00,0.02 \pm 0.00$ and $0.04 \pm 0.01 \mathrm{f} / \mathrm{cc}$ for $\mathrm{PF}_{1}, \mathrm{PF}_{2}, \mathrm{PF}_{3}$ and $\mathrm{PF}_{4}$, respectively.

The studied plastic filler samples contain asbestos fibers in the following decreasing order; $\mathrm{PF}_{4}>\mathrm{PF}_{1}>\mathrm{PF}_{3}>$ and $\mathrm{PF}_{2}$ as shown in Figure 3.

The presence of asbestos in the studied plastic filler samples could be due to the contamination of materials uses in its production with asbestos or advertently used to increase the flame retardancy of plastic products made with plastic fillers.

The levels asbestos in the plastic filler samples were within the recommended permissible limits.

Chrysotile had long been implicated as a critical material in the manufacture of building materials especially floor and ceiling tiles [21]. Although its use has been banned, so many powerful countries of the world still add it as an ingredient in the manufacture of building materials based on its flexibility and excellent insulating properties [22].

Results of Table 4 show that the mean levels of asbestos fiber in the studied 
Table 3. Mean asbestos fiber contents in the plastic filler samples sold within Enugu metropolis.

\begin{tabular}{cc}
\hline Sample & Asbestos fiber content $(\mathrm{f} / \mathrm{cc})$ \\
\hline $\mathrm{PF}_{1}$ & $0.03 \pm 0.01$ \\
$\mathrm{PF}_{2}$ & $0.01 \pm 0.00$ \\
$\mathrm{PF}_{3}$ & $0.02 \pm 0.00$ \\
$\mathrm{PF}_{4}$ & $0.04 \pm 0.01$ \\
Permissible limit $[14]$ & 0.2 \\
\hline
\end{tabular}

$\mathrm{PF}=$ Plastic filler.

Table 4. Mean asbestos fiber contents in the ceiling tile samples sold within Enugu metropolis.

\begin{tabular}{cc}
\hline Sample & Asbestos fiber content $(\mathrm{f} / \mathrm{cc})$ \\
\hline $\mathrm{CT}_{1}$ & $\mathrm{ND}$ \\
$\mathrm{CT}_{2}$ & $0.06 \pm 0.01$ \\
$\mathrm{CT}_{3}$ & $0.04 \pm 0.02$ \\
$\mathrm{CT}_{4}$ & $0.06 \pm 0.02$ \\
$\mathrm{CT}_{5}$ & $0.03 \pm 0.00$ \\
Permissible limits $[14]$ & 0.2 \\
\hline
\end{tabular}

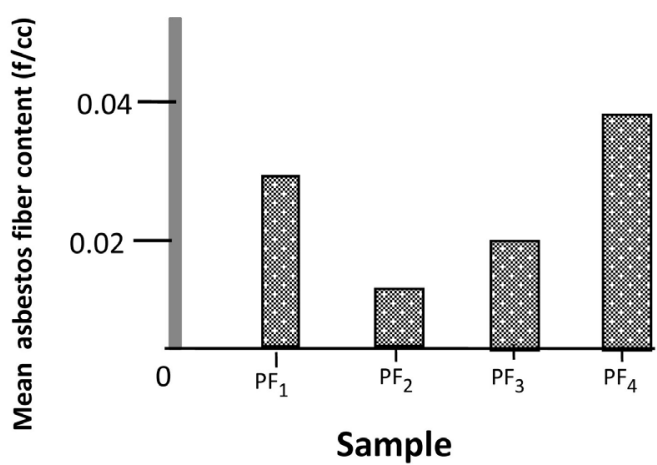

Asbestos fiber content (f/cc)

Figure 3. Bar chart representation of the mean levels of asbestos fiber in the plastic filler samples.

ceiling tile samples were $0.06 \pm 0.01,0.04 \pm 0.02,0.06 \pm 0.02$ and $0.03 \pm 0.00 \mathrm{f} / \mathrm{cc}$ for $\mathrm{CT}_{2}, \mathrm{CT}_{3}, \mathrm{CT}_{4}$ and $\mathrm{CT}_{5}$ respectively.

The ceiling tile samples contain asbestos fiber in the following decreasing order; $\mathrm{CT}_{2}>\mathrm{CT}_{4}>\mathrm{CT}_{3}>\mathrm{CT}_{5}$ as shown in Figure 4.

The levels of asbestos fiber in the ceiling samples were within the recommended permissible limits.

\section{Conclusions}

$90 \%$ of the cosmetic (talc powders) and non-cosmetic (gauze pads, plastic fillers and ceiling tiles) sample products investigated had asbestos fiber although within the recommended permissible limits. 


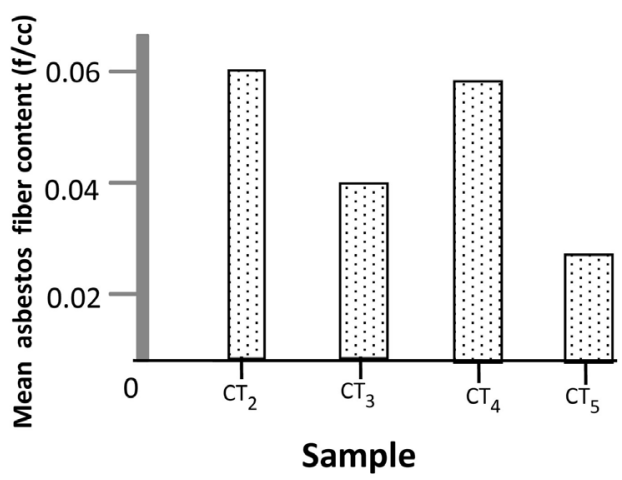

Asbestos fiber content (f/cc)

Figure 4. Bar chart representation of the mean levels of asbestos fiber in the ceiling tile samples.

The study shows that both foreign and locally produced cosmetic and non-cosmetic items in our markets are not free from asbestos, a very well known hazardous substance, despite its proclaimed ban in so many countries of the world.

Although the studied samples had asbestos fiber at non-toxic levels, however, the friability of asbestos fibers in sample products such as talc powder could portend greater danger to infants and the elderly especially at consistent use.

Despite the excellent properties of asbestos that necessitate its use in the industry, it is important that countries of the world should strictly enforce the ban on the use of items that contains asbestos through strict, mandatory and periodic evaluation of all items that fall within its industrial and household applications.

\section{Acknowledgements}

The authors of the research are immensely grateful to the management of Scientific Equipment Development Institute, Enugu and Nnamdi Azikiwe University, Awka, for allowing us to use their chemical laboratory for the analysis of the research samples. We equally immeasurably thank all those who one way or the other helped to make this research a great success.

\section{Conflicts of Interest}

The authors declare no conflicts of interest regarding the publication of this paper.

\section{References}

[1] Karunaratne, P.C.T. and Fernando, W.A.G. (2015) Characterization and Radiation Impact of Corrugated Asbestos Roofing Sheets in Sir Lanka. Journal of Geological Society of Sir Lanka, 17, 31-40.

[2] Malcolm, R. and Nolan, R.P. (2008) History of Asbestos Discovery and Use and Asbestos-Related Disease in Context with the Occurrence of Asbestos within the Ophiolite Complexes: Geological Society of America. Special Paper 373, 2373-2382.

[3] Hwang, S. and Park, W. (2016) Application of Asbestos Management Index and 
Asbestos Recognition in Public Buildings in South Korea. Human Ecological Risk Assessment, 22, 1542-1551. https://doi.org/10.1080/10807039.2016.1197768

[4] Harvey, B., Perkins, R., Nickerson, J. and Beard, M. (2011) Formulating Bulk Asbestos Standards. Asbestos Issues, 14, 122-129.

[5] Selikoff, I.J. (2012) Asbestos and Disease. Mineralogist, 88, 1110-1124.

[6] Gaia, M.M., Elias, S., Adrian, Y.G., Federico, M. and Lara, G. (2019) The Concentration of Asbestos Fibers in Bulk Samples and Its Variation with Grain Size. Minerals, 9, 531-539. https://doi.org/10.3390/min9090539

[7] Lim, J.W., Koh, D., Klim, J.S., Le, G.V. and Takaheshi, K. (2011) Preventive Measures to Eliminate Asbestos-Related Diseases in Singapore. Safety and Health at Work, 2, 203-209. https://doi.org/10.5491/SHAW.2011.2.3.201

[8] Takashashi, K. (2008) Asian Asbestos Initiative. Asbestos-Related Diseases: Time for Technology Sharing. Occupational Medicine, 58, 384-401. https://doi.org/10.1093/occmed/kqn086

[9] Lee, P.N. (2001) Relation between Exposure to Asbestos and Smoking Jointly and Risk of Long Cancer. Occupational Environmental Medicine, 58, 145-153. https://doi.org/10.1136/oem.58.3.145

[10] Kang, S.K. and Kim, E.A. (2010) Occupational Disease in Korea. Journal of Korean Medical Science, 25, S4-S12. https://doi.org/10.3346/jkms.2010.25.S.S4

[11] Agency for Toxic Substances and Disease Registry (2019) Toxicological Profile for Asbestos. US Department of Health and Human Services, Public Service. https://www.atsdr.cdc.gov/toxprofiles/tp61

[12] Le, G.V., Takahashi, K., Park, E.K., Delgermaa, V., Oak, C. and Algonid, S.M. (2011) Asbestos Related Diseases in Asia: Past, Present and Future. Respirology, 16, 767-775. https://doi.org/10.1111/j.1440-1843.2011.01975.x

[13] Robinson, B.W., Mosk, A.W. and Lake, R.A. (2005) Malignant Mesothelioma. The Lancet, 366, 397-408. https://doi.org/10.1016/S0140-6736(05)67025-0

[14] World Health Organization (2014) Air Quality Guidelines. 2nd Edition, Asbestos Regional Office for Europe, Copenhagen, 117-123.

[15] American Standard for Testing of Materials (2015) ASTM D6281-15; Standard Test Method for Air Borne Asbestos Concentration in Ambient and Indoor Atmosphere as Determined by Transmission Electron Microscopy Direct Transfer (TEM). ASTM International, West Conshohocken, 11:07-11.

[16] American Standard for Testing of Materials (2016) ASTM-1; Standard Test Method for Determination of Asbestos in Soil. Designation: D7521-16.

https://www.astm.org

[17] Berge, W., Mundt, K. and Luu, H. (2018) General Use of Talc and Risk of Ovarian Cancer. A Meta-Analysis. European Journal of Cancer Review, 27, 248-257. https://doi.org/10.1097/CEJ.0000000000000340

[18] Cook, L.S., Kamb, M.L. and Weiss, N.S. (1997) Perineal Powder Exposure and the Risk of Ovarian Cancer. American Journal of Epidemiology, 145, 459-465. https://doi.org/10.1093/oxfordjournals.aje.a009128

[19] Cramer, D.W., Victonis, A.F. and Terry, K.L. (2016) The Association between Talc Use and Ovarian Cancer: A Retrospective Case Control Study in Two US States. Epidemiology, 27, 334-346. https://doi.org/10.1097/EDE.0000000000000434

[20] Bellon, T. (2018) Jurg Orders J \& J to Pay \$48 Billion in Missouri Asbestos Cancer Case. https://www.renters.com/article/US-johnson-johnsoncancer-lawsuit

[21] Kim, H.R. (2009) Overview of Asbestos Issues in Korea. Journal of Korean Medical 
Sciences, 24, 363-377. https://doi.org/10.3346/jkms.2009.24.3.363

[22] Gualtieri, A.F. and Tarbaglia, A. (2010) Thermal Decomposition of Asbestos and Recycling in Traditional Ceramics. Journal of the European Ceramic Society, 40, 2409-2418. 